\title{
Determinants of biopharmaceutical R\&D expenditures in China: the impact of spatiotemporal context
}

\author{
Jiafeng $\mathrm{Gu}^{1}{ }^{(0)}$ \\ Received: 9 September 2020 / Accepted: 20 May 2021 / Published online: 23 June 2021 \\ (c) Akadémiai Kiadó, Budapest, Hungary 2021
}

\begin{abstract}
The spatiotemporal context affects corporate behavior because any corporate activity is carried out in a specific time and space. Based on an examination on the research and development (R\&D) expenditures of 284 listed biopharmaceutical companies in China, this study finds that the innovation space of the biopharmaceutical industry presents a spatial "North-South" pattern. The spatial gravity center of the biopharmaceutical industry's R\&D investment has been shifting to the eastern coastal region. This spatiotemporal context will impact the R\&D investment of biopharmaceutical companies. Research shows that the distance between biopharmaceutical companies and the gravity center has a direct impact on the R\&D expenditures of biopharmaceutical companies. This study supports the context-sensitive thesis and shows how the spatiotemporal context affects the R\&D investment of biopharmaceutical companies while controlling firm-level factors.
\end{abstract}

Keywords R\&D $\cdot$ Spatiotemporal content $\cdot$ Spatial spillover $\cdot$ Pharmaceuticals $\cdot$ China

\section{Introduction}

Innovation is a critical source to gain a competitive advantage in enterprises (Kodama, 2017; Menke, 1997). Enterprises need to invest in research and development (R\&D), create new products or processes, and develop new products to seize market share (Philippe et al., 2013). In the biopharmaceutical industry, R\&D investment is an essential guarantee for biopharmaceutical companies' profits (David et al., 2009; Scherer, 2001). It has been well established that firm-level attributes, such as firm age, firm size, and corporate financial performance, are associated with $\mathrm{R} \& \mathrm{D}$ expenditure in the biopharmaceutical industry (DiMasi, 2014; Nivoixa \& Nguyen, 2012; Scherer, 2001; Schmutz \& Santerre, 2013; Taggart, 2007). However, whether or not contextual level affects R\&D expenditure in the biopharmaceutical industry, with contexts defined as macro-level conditions in terms of either region or time, remains controversial. Many researchers have attempted to incorporate spatial factors into the determinants of $R \& D$ investment over the past 30 years (Cabrer-Borras

Jiafeng Gu

isssgujf@pku.edu.cn

1 Institute of Social Science Survey, Peking University, Room 445, Science Building 5, No.5

Yiheyuan Road, Beijing 100871, China 
\& Serrano-Domingo, 2007; Cellini \& Lambertini, 2009; Goel \& Haruna, 2007; Kleinknecht \& Poot, 1992; Smrkolj \& Wagener, 2016; Spithoven \& Eacute, 2002). This viewpoint is referred to as a "context-sensitive" thesis. However, the exact mechanism remains elusive. The spatiotemporal context-strategic interaction-performance (SSP) theory proposed by $\mathrm{Gu}(2021 \mathrm{~b})$ provides a potential theoretical explanation for the context-sensitive thesis.

This study hypothesizes that the spatiotemporal context will affect R\&D expenditure in the biopharmaceutical industry. To test this hypothesis, the spatial distribution and trend of R\&D investment in the biopharmaceutical industry in China are examined, and the strategic interactions of Chinese biopharmaceutical enterprises in R\&D are analyzed. Moreover, core factors, including spatial distance and time, are incorporated into the empirical model. These tests provide significant opportunities for empirical evaluations of the context-sensitive thesis on the relationship between the spatiotemporal context and R\&D expenditure in the biopharmaceutical industry. To achieve the above-mentioned research goals, the remainder of this paper is arranged as follows: Sect. "China's biopharmaceutical industry and its R\&D", introduces China's biopharmaceutical industry and its R\&D. The basic theory and core concept of spatial competition in the biopharmaceutical industry are expounded in Sect. "Spatial competition of biopharmaceutical R\&D", while the data, samples, and methods are introduced in Sect. "Material and method". The results of the empirical research are introduced and discussed in Sect. "Results and discussion", while the conclusion is presented in Sect. "Conclusion".

\section{China's biopharmaceutical industry and its R\&D}

Biopharmaceutical firms in China generally refer to firms that produce biopharmaceuticals by means of genetic engineering, antibody engineering, or cell engineering technologies for the diagnosis, prophylaxis, and treatment of diseases (Kai and Wang, 2012). The R\&D of biotechnological drugs in China started late, and it was not until the early 1970s that recombinant DNA technology was applied to medicine. However, with the strong support of the national industrial policy (especially the national "863" high-tech program), this field has developed rapidly in China, thereby gradually narrowing the gap with advanced countries. The biopharmaceutical industry is one of China's key strategic emerging industries. In 2009, China issued several policies to promote the accelerated development of the biological industry to strengthen the R\&D of the biotechnology industry. According to the healthcare information company IQVIA, China was the world's second-largest national biopharmaceutical market in 2017, worth US\$ 122.6 billion. It is also reported to be the biggest emerging market for biopharmaceuticals, with its growth tipped to reach US\$ 145 billion to US\$ 175 billion by 2022 (Tan, 2018).

In the early stages of development, owing to the lack of R\&D funding, most Chinese biopharmaceutical companies adopted a technological development strategy of "imitation as the mainstay and innovation as the supplement." In 2008, through the third revision of the "Patent Law," China adopted the "relative novelty" standard, and the number of biomedical patents began to increase. Chinese biopharmaceutical companies protect their R\&D results by applying for patents. According to the "2019 China Life Science and Biotechnology Development Report" issued by the Ministry of Science and Technology of China, in 2018, China ranks second in the world in terms of the number of patent applications and authorizations in the fields of life sciences and biotechnology (MOST, 2019). IPRdaily, the intellectual property industry media, 
released the "2019 Global Biomedical Industry Invention Patent Ranking (TOP100)" with seven Chinese companies featuring on the list (IPRdaily, 2019).

With the rapid growth of China's biopharmaceutical industry, R\&D investment has shown a continuous increase (Zhenzhen et al., 2004). In the initial stage, biopharmaceutical companies in China focused on generic drugs with quick results and low R\&D costs (Chen et al., 2018). This is the current R\&D investment behavior that emphasizes short-term benefits. After accumulating technical and management experience in the R\&D of generic drugs, an increasing number of biopharmaceutical companies in China have invested substantial capital in the R\&D of new drugs to build their strengths and become more competitive in the domestic and international markets (Langer \& Zhou, 2007). Such R\&D activities are innovative and are an important foundation for Chinese biopharmaceutical companies to build their core competitiveness.

In the early stages of development, Chinese biopharmaceutical companies generally adopt the R\&D approach for generic drugs through the "import substitution" strategy to occupy a place in the domestic market. With the strong support of the government and the efforts of the enterprises themselves, China's biopharmaceutical industry has become increasingly closely connected with the international market, and exports have been growing steadily (Conlé, 2019). In the EU and Japanese markets, China's biopharmaceutical industry exports have a much higher market share than other countries and regions, and they account for one of the highest proportions in the US market. At present, several COVID-19 vaccines developed by Chinese biomedical companies are being exported to over 60 countries worldwide (Cohen, 2020). These results indicate that China's biopharmaceutical industry is highly competitive in the international export market. China is certainly a leader in the biopharmaceutical field (Breithaupt, 2003), and it has achieved excellent performance (Y. C. Zhang \& Li, 2009).

China and India have similar paths in the development of biopharmaceuticals, and policies have played an important role in this context. In the late 1970s, India promulgated the first "Patent Law," which stipulated that if the original production process or process of the drug concerned was changed, the product would no longer be subject to patent restrictions. This has significantly stimulated the development and production of generic drugs in India (Chakraborty \& Agoramoorthy, 2010). After 2005, India began to protect the patents of drugs, and it introduced a series of preferential fiscal and tax policies to encourage R\&D to promote the independent research and development of new drugs by Indian biopharmaceutical companies. In 1985, China enacted its first "Patent Law," which only protected the production process of medicines, but did not protect the medicines themselves. Therefore, China's biopharmaceutical industry has gradually developed through imitation. In the 1990s, China adjusted its drug intellectual property policies and implemented the conditional administrative protection of drugs. In 1992 and 2000, the "Patent Law" was revised successively, thus effectively promoting $\mathrm{R} \& \mathrm{D}$ and independent intellectual property rights of new drugs. At present, the drug intellectual property policies of the two countries have complied with international standards. Now, the policy objectives of India and China aim to nurture an innovation ecosystem and a vibrant bioeconomy with greater ambitions for exports from the sector (Greenlund et al., 1995). Therefore, research on China's biopharmaceutical industry is helpful toward exploring effective paths for the development of the biopharmaceutical industry in emerging economies and plays an important reference role in the development of the biopharmaceutical industry in many developing countries. 


\section{Spatial competition of biopharmaceutical R\&D}

With the intensification of the competition in the biopharmaceutical industry, biopharmaceutical companies have been increasing $R \& D$ investment, leading to the continuous growth of R\&D expenditures in the biopharmaceutical industry (Golec \& Vernon, 2008). This increment in R\&D expenditures by these companies produces a positive wealth effect (Liao \& Lin, 2017). External factors, such as the patent system (Schroeder, 2007), price control (Golec \& Vernon, 2010), and economic development (Raghavendra et al., 2012), affect the R\&D expenditures of biopharmaceutical companies. These factors are related to space and region (Eckhardt, 2004; Kleinknecht \& Poot, 1992). Research on the impact of space on enterprise $R \& D$ investment has been generally conducted using the Hotelling model (Matsumura \& Matsushima, 2012). In the R\&D competition of the Hotelling model, two biopharmaceutical companies are located somewhere between 0 and 1 of the Hotelling line. To pursue profit maximization, the result of the competition is that each company tends to concentrate on the market center, namely the principle of minimum differentiation (Hotelling, 1929; Iskakov \& Pavlov, 2009).

The Hotelling model deals with the competition between the points on the line, which connotes a linear competition (Atewamba \& Nkuiya, 2017). However, in reality, many enterprises conduct dynamic competition on a spatial plane, thus it is necessary to extend this model to the spatial plane, such as discussing the conditions for obtaining Hotelling equilibrium in a circular space (Hayashi \& Tsuge, 2019). In a circular space, the center of a market is generally the center of gravity of the circle (Kulin \& Kuenne, 1962; Tellier \& Vertefeuille, 2006). In the spatial competition of biopharmaceutical enterprises, the principle of minimum differentiation still applies, that is, there will be a market center, which is the center of gravity of the circle reflected in the space. For example, the spatial center of global biopharmaceutical companies has shifted from the confluence of Germany, Switzerland, and France to the US (Daemmrich, 2009). With the rapid development of the biopharmaceutical industry in China, the spatial gravity center of global biopharmaceutical companies' R\&D is shifting toward China (Daemmrich, 2009). Regional R\&D centers have been formed and spatial aggregation of biopharmaceutical companies can be observed, including the cluster of quality biopharmaceutical companies and R\&D investment in Boston, San Francisco, and San Diego in the US, Toronto and Montreal in Canada, and Munich, Stockholm, Oxford, and Cambridge in Europe (Cooke, 2004). The formation of R\&D's spatial gravity center in the biopharmaceutical industry has a significant impact on the R\&D investment of biopharmaceutical enterprises. In terms of R\&D investment, biopharmaceutical companies tend to concentrate on and approach the spatial gravity center of $\mathrm{R} \& \mathrm{D}$, which is the embodiment of the principle of minimum differentiation of the Hotelling model in plane space.

The influence of space factors on the R\&D investment of biopharmaceutical companies is not static, but dynamic, that is, it is affected by time factors (Breton et al., 2004). In the dynamic Hotelling model, there will be strategic interaction between competitive enterprises, and the distance between competitive enterprises will impact enterprises' R\&D investment (Abdelaziz et al., 2008; Li \& Zhang, 2013). For biopharmaceutical companies, the closer they are to the spatial gravity center of the biopharmaceutical industry's R\&D investment, the more they can take advantage of the spatial spillover effect of technological innovation. Therefore, the higher their investment in R\&D will be (Breton et al., 2006; Watanabe et al., 2002). With the concept of time, the spatial gravity center of the biopharmaceutical industry's R\&D investment will shift and the companies' investment strategy 
will also adjust with the change (Schuhmacher et al., 2016). Hence, the spatiotemporal context of a biopharmaceutical enterprise has a dynamic impact on its R\&D investment.

In general, the R\&D expenditure of biopharmaceutical companies is determined by external and internal factors (Higon et al., 2010). The R\&D investments of biopharmaceutical companies are determined according to their spatiotemporal context and individual factors. At the company level, the size of an enterprise often has a significant influence on its R\&D investment (Chung et al., 2019; DiMasi, 2014; Philippe et al., 2013). Other factors at the company level include company sales (Prentis et al., 1988), company earnings (David et al., 2009), corporate governance structure (Jing \& Gou, 2010), tax burden (William \& McCutchen, 1993), and labor costs (Omta et al., 1994). Therefore, it is necessary to explore the influence mechanism of these factors on $R \& D$ investment in a specific spatiotemporal context.

\section{Material and method}

\section{Sample}

In this study, the panel data of 284 biopharmaceutical companies listed in the Shanghai and Shenzhen stock markets from 2015 to 2018 are selected as research samples. The 284 biopharmaceutical listed companies cover seven major fields, including chemical raw materials, chemical preparations, biological products, medical services, medical devices, biopharmaceutical commerce, and traditional Chinese medicine, covering 30 provinces in China. There are three reasons for choosing 2015 as the starting point for the study: first, since 2015, several biopharmaceutical companies with comprehensive financial data and information disclosure have been listed on the exchanges. In 2015, the "Proposals of the Central Committee of the Communist Party of China on Formulating the Thirteenth Five-Year Plan for National Economic and Social Development" was issued, and the development of biomedicine was planned at the national level, and it was elevated to a national strategic industry. The second reason is to eliminate companies with incomplete data disclosures and large abnormal data fluctuations. Third, ST (listed companies that have suffered losses due to their business operations for two consecutive years and have been specially dealt with) and *ST (listed companies that have suffered losses for three consecutive years and have been warned of delisting) companies are excluded. These companies are not well managed, in a state of financial loss, and even face the risk of being unable to reverse or go bankrupt. The inclusion of these companies will mislead the research conclusion, thus these companies need to be excluded. The data allow us to examine spatial and temporal patterns in the relationship between the contextual level of the biopharmaceutical industry and R\&D expenditure of biopharmaceutical companies while controlling firm-level factors.

\section{Variable measurement}

Dependent variables $\mathrm{R} \& \mathrm{D}$ expenditure(RDE)the explained variable, is an important and widely used indicator to measure an enterprise's R\&D investment (Chakma et al., 2014; Spithoven \& Eacute, 2002). Patents are widely used as innovation indicators and are also controversial (Daniele, 1992). Conversely, measuring enterprise innovation from the perspective of $R \& D$ input can effectively reflect the true investment of enterprises in R\&D (Wang, 2010). By increasing R\&D investment, biopharmaceutical enterprises 
can enhance their competitiveness and consolidate their competitive advantages in the market (Golec \& Vernon, 2008; Scherer, 2001). Notably, R\&D expenditure is one of the most widely used measures of innovation inputs in the biopharmaceutical field (Hsieh \& Lofgren, 2009; Glaser 1995). Thus, the logarithm of the R\&D expenditure (lnRDE) of biopharmaceutical enterprises is used here.

Explanatory variables Explanatory variables are divided into three parts: the first part is the variable "distance," used to measure the geographical distance between the biopharmaceutical company's location and the spatial gravity center of the biopharmaceutical industry's R\&D investment. This distance is the core attribute in spatiotemporal context analysis $(\mathrm{Gu}, 2021 \mathrm{a}, \mathrm{b})$. In the innovation competition landscape, this distance is a bridge for the spatiotemporal context that influences micro-enterprises' innovation activities (Gu, 2020). Because this spatial gravity center changes annually, the distance from the biopharmaceutical companies to this spatial gravity center varies yearly, even if the biopharmaceutical company's location remains the same. As biopharmaceuticals generally form spatial clusters of technology, talents, and funds, R\&D investment is more sensitive to distance (Kim et al., 2009). Thus, in the empirical models, the numerical quadratic of the distance is used as the independent variable.

The second part is the variables of biopharmaceutical companies. The company's size has a significant impact on the R\&D expenditure of biopharmaceutical enterprises (Chung et al., 2019; DiMasi, 2014). In this study, two variables, the logarithm of total assets (InTA) and the logarithm of total employees (lnTE), are used to measure the size of biopharmaceutical enterprises. Explanatory variables also include logarithm of sales expense as a percentage of gross revenue (lnSE) (Prentis et al., 1988), return on equity (ROE) (David et al., 2009), logarithm of the shareholding ratio of the top 10 shareholders (lnSTS) (Jing \& Gou, 2010), logarithm of taxes payable as a percentage of gross revenue (lnTP) (William \& McCutchen, 1993), and logarithm of staff salaries as a percentage of gross revenue (lnSS) (Omta et al., 1994). The third part is the variable of time used to investigate the time effect in different years. The symbols and definitions of relevant explanatory variables are summarized in Table 1.

Furthermore, the latitude and longitude data of the sample company addresses are collected to calculate the spatial distance.

Table 1 Variable symbols and definitions

\begin{tabular}{ll}
\hline Variable symbols & Variable definitions \\
\hline lnRDE & Logarithm of R\&D Expenditures (Ten Thousand Yuan) \\
Distance & $\begin{array}{c}\text { Geographical Distance Between the Location of the Biophar- } \\
\text { maceutical Company and the Spatial Gravity Center of the }\end{array}$ \\
& Biopharmaceutical Industry's R\&D Investment (Kilometer) \\
$\operatorname{lnTA}$ & Logarithm of Total Assets (100 Million Yuan) \\
$\operatorname{lnTE}$ & Logarithm of Total Employees \\
$\operatorname{lnSE}$ & logarithm of Sales Expenses / Gross Revenue \\
ROE & Return on Equity \\
$\operatorname{lnSTS}$ & Logarithm of Shareholding ratio of the Top 10 Shareholders \\
$\ln \mathrm{TP}$ & Logarithm of Taxes Payable / Gross Revenue \\
$\operatorname{lnSS}$ & Logarithm of Staff Salaries / Gross Revenue \\
\hline
\end{tabular}




\section{Descriptive statistics}

In this study, 1136 observed values are obtained through the preliminary processing of the above-mentioned data. The descriptive statistics are shown in Table 2, including the number of observed values, mean value, standard deviation, minimum value, and maximum value of each variable from left to right.

\section{Methods}

\section{Standard deviational ellipse analysis}

In this study, D. Welty Lefever's standard deviational ellipse (SDE) method is used to measure the spatial gravity center of the biopharmaceutical industry (Gong, 2002).

\section{Spatial correlation test}

The strategic interaction between biopharmaceutical companies can be analyzed using a spatial autocorrelation test. The most commonly used test method is Moran's I index, whose formula is:

$$
I=\frac{\sum_{i=1}^{n} \sum_{j=1}^{n} w_{i j}\left(x_{i}-\bar{x}\right)\left(x_{j}-\bar{x}\right)}{s^{2}} i-1,2, \ldots, 284 ; j=1,2, \ldots, 284
$$

where $x_{i}$ is the R\&D expenditure of the $i$ biopharmaceutical company, and $n=284$ is the total number of biopharmaceutical companies; $w_{i j}$ is an element of the spatial weight matrix. An inverse distance spatial weight matrix is used: the greater the distance between each other, the smaller the weight; $S^{2}=\sum_{i=1}^{n}\left(x_{i}-\bar{x}\right)^{2} / n$ is the variance of the sample; and $\bar{x}=\sum_{i=1}^{n} x_{i} / n$ is the average of the sample.

\section{Spatial regression analysis}

Using the inverse distance spatial matrix and considering the spatial lag effect of biopharmaceutical companies' $R \& D$ expenditures, three spatial panel regression models are established.

In Model 1, there is a spatial lag effect of the dependent variables. The basic model is presented as follows:

$$
\begin{aligned}
\ln R D E_{u}= & C+\rho W \ln R D E_{i t}+\beta_{1} d i s \tan c e_{i t}^{2}+\beta_{2} \ln T A_{i t}+\beta_{3} \ln T E_{i t}+\beta_{4} \ln S E_{i t} \\
& +\beta_{5} R O E_{i t}+\beta_{6} \ln S T S_{i t}+\beta_{7} T P_{i t}+\beta_{8} \ln S S_{i t}+\varepsilon_{i t}, \varepsilon_{i t} \sim N\left(0, \sigma^{2} I_{n}\right) \\
& i=1,2, \ldots, 284 ; t=2015,2016,2017,2018 .
\end{aligned}
$$

In Model 2, there is a spatial lag effect on the independent variable (lnTA). The basic model is presented as follows:

$$
\begin{aligned}
\ln R D E_{u}= & C+\gamma W \ln T A_{i t}+\beta_{1} d i s \tan c e_{i t}^{2}+\beta_{2} \ln T A_{i t}+\beta_{3} \ln T E_{i t}+\beta_{4} \ln S E_{i t} \\
& +\beta_{5} R O E_{i t}+\beta_{6} \ln S T S_{i t}+\beta_{7} T P_{i t}+\beta_{8} \ln S S_{i t}+\varepsilon_{i t}, \varepsilon_{i t} \sim N\left(0, \sigma^{2} I_{n}\right) \\
& i=1,2, \ldots, 284 ; t=2015,2016,2017,2018 .
\end{aligned}
$$




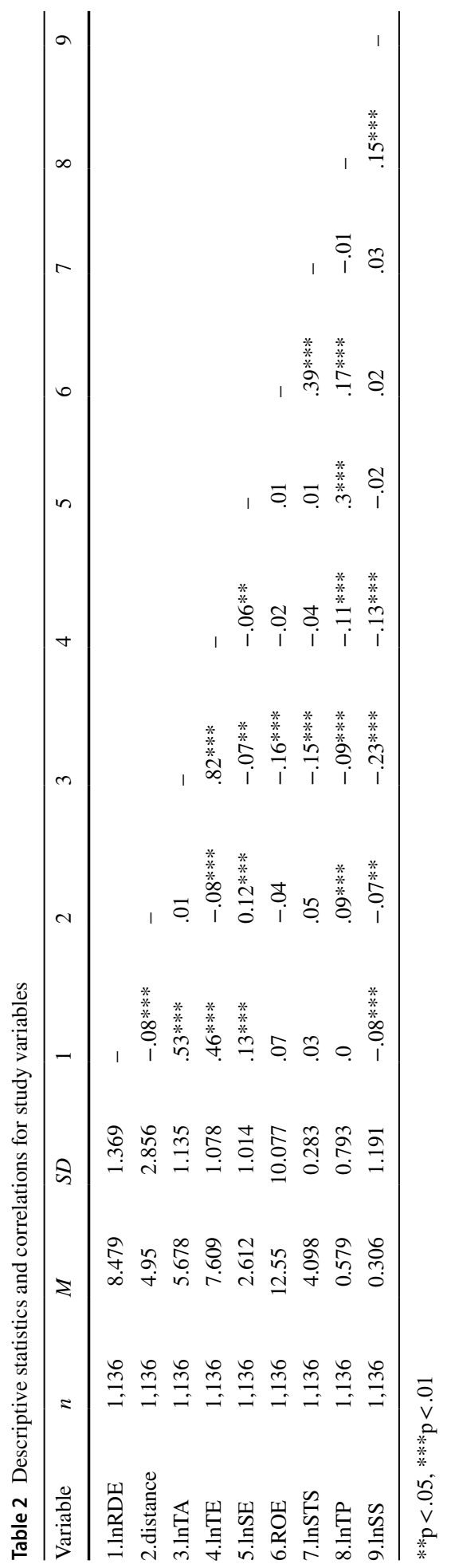


In Model 3, there is a spatial lag effect on the independent variable (lnTE). The basic model is presented as follows:

$$
\begin{aligned}
\ln R D E_{u}= & C+\gamma W \ln T E_{i t}+\beta_{1} d i s \tan c e_{i t}^{2}+\beta_{2} \ln T A_{i t}+\beta_{3} \ln T E_{i t}+\beta_{4} \ln S E_{i t} \\
& +\beta_{5} R O E_{i t}+\beta_{6} \ln S T S_{i t}+\beta_{7} T P_{i t}+\beta_{8} \ln S S_{i t}+\varepsilon_{i t}, \varepsilon_{i t} \sim N\left(0, \sigma^{2} I_{n}\right) \\
& i=1,2, \ldots, 284 ; t=2015,2016,2017,2018 .
\end{aligned}
$$

Models 2 and 3 mainly explore the direct and indirect impacts of the size of biopharmaceutical enterprises on $R \& D$ investment. In the actual regression process, the time effect is considered; therefore, the year is also modeled as an independent variable.

\section{Results and discussion}

\section{Spatial gravity center of the R\&D investment and its evolution}

The spatial distribution of the 284 listed biopharmaceutical companies' R\&D expenditures in China from 2015 to 2018 is shown in Fig. 1. In Fig. 1, the dotted line ellipse is the SDE of the biopharmaceutical industry's R\&D investment in 2015. The solid line ellipse is the SDE of the biopharmaceutical industry's R\&D investment in 2018. In Fig. 1, the two small red dots represent the spatial gravity center of the biopharmaceutical industry's R\&D investment in 2015 and 2018. The one on the left is the spatial gravity center of 2015 , while the one on the right is the spatial gravity center of 2018. From the shape of the ellipse, the distribution range of the ellipse is concentrated in southeast China, presenting a "North (slightly east)-South (slightly west)" spatial distribution pattern. The spatial distribution of China's biopharmaceutical industry's overall R\&D investment has an evident central-peripheral structure. The core of the biopharmaceutical companies lies in the eastern coastal area, with substantial investments in the R\&D of China's biopharmaceutical industry. Its SDE is mainly distributed in the North China Plain and the middle and lower Yangtze River plains.

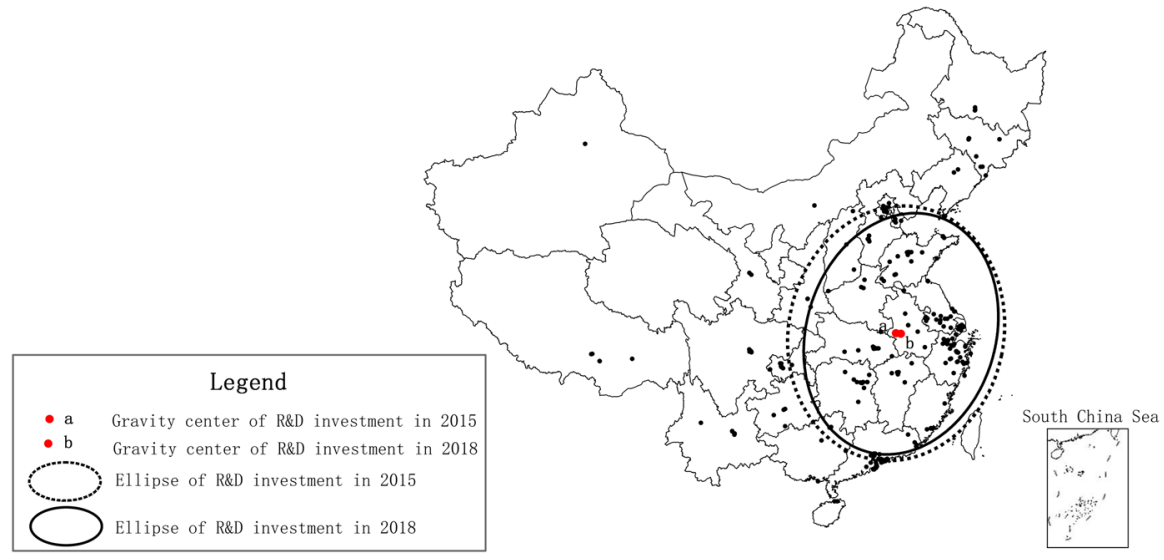

Fig. 1 Spatial gravity center of R\&D investment 
The small black dot in Fig. 1 represents the 284 listed biopharmaceutical companies. From the spatial distribution of these small black spots, it is evident that there is a spatial aggregation phenomenon. These small black spots are mainly concentrated in the Yangtze River Delta, Bohai Rim, and the Pearl River Delta. This indicates that China's biopharmaceutical industry has initially formed an industrial spatial pattern with the Yangtze River Delta, Bohai Rim, and Pearl River Delta as its core. As shown in Fig. 1, the SDE of the biopharmaceutical industry's R\&D investment in 2018 is smaller than that in 2015. This shows that, from the perspective of spatial distribution, the biopharmaceutical industry has evident spatial convergence in R\&D investment. This indicates that although the growth of this investment in these enterprises is unbalanced, it generally shows the characteristics of convergence, namely, the equilibrium is reached through convergence (Egger \& Pfaffermayr, 2006). In the linear Hotelling model, to pursue profit maximization, every enterprise tends to concentrate in the market center and has a definite "centralization" desire (Hotelling, 1929). This study shows that even in a flat space, biopharmaceutical companies distributed all over China still have a strong desire to "centralize" and try to get as close to the spatial gravity center of the biopharmaceutical industry's R\&D investment as much as possible. As a result of this competition, the integrative biopharmaceutical industry's R\&D space will become increasingly convergent. This is the inevitable process of the circular Hotelling model in approaching equilibrium (Cooke, 2004; Hayashi \& Tsuge, 2019).

Figure 2 shows the specific location of the spatial gravity center of the biopharmaceutical industry's R\&D investment from 2015 to 2018. Although these gravity centers in the past four years have been in Huoshan County, Liuan City, Anhui Province, there has been a shift every year. From 2015 to 2016, the gravity center shifted to the southeast; from 2016 to 2017 , it moved to the northeast; from 2017 to 2018 , it shifted to the southeast. It can be seen that, on the whole, from 2015 to 2018 , the gravity center shows an evident trend of a shift from west to east. The main reason for this shift is that the R\&D investment of these

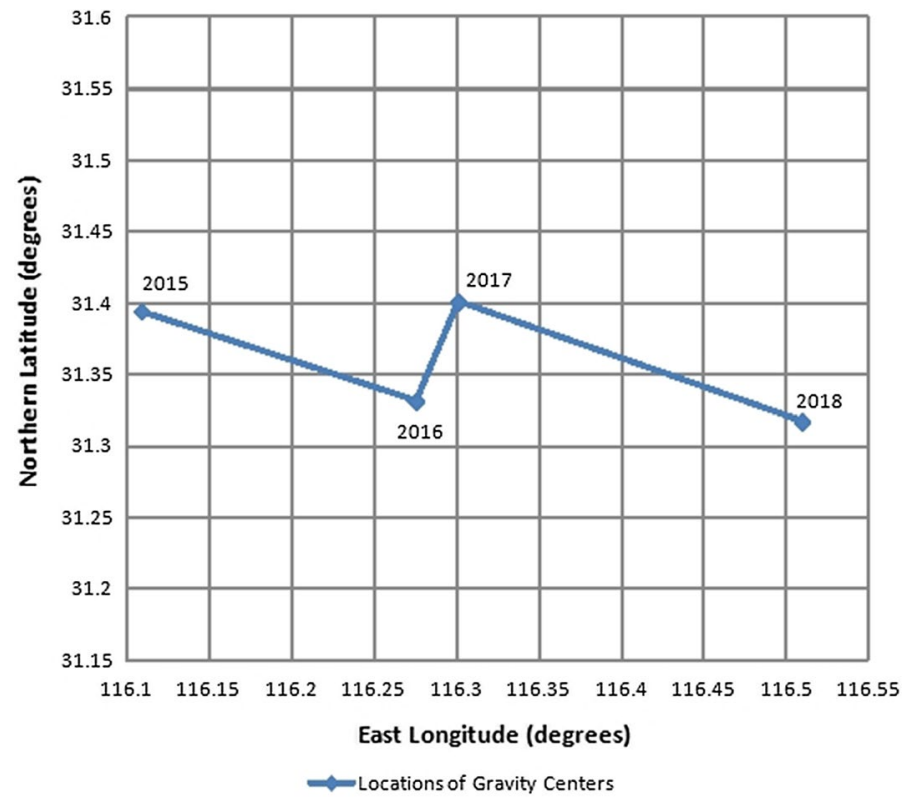

Fig. 2 Spatial shifts of the gravity center of $R \& D$ investment 
companies in the eastern coastal areas increases more rapidly than in the western regions. Weber (1929) reports that finding the location of the minimum transport cost is the same as finding the equilibrium point of a force system acting on a point in two-dimensional space in physics. In the two-dimensional space, when more force is exerted at one point, the equilibrium point shifts in this direction. This study shows that biopharmaceutical companies in the eastern coastal areas continue to increase their R\&D investment, leading to a shift in the spatial gravity center of these companies' R\&D investment toward the east. As indicated by Kulin and Kuenne (1962), the center of gravity is a convenient starting point for the Weber problem algorithm. This study confirms Kulin and Kuenne (1962) inference that any movement of the center of gravity would involve the corresponding movement of all the points of maximum gravity potential. In this study, it is established that most of these points of maximum gravitational potential are distributed in the eastern coastal area.

\section{Strategic interaction of biopharmaceutical companies' R\&D investment}

In the classical linear Hotelling model, there must be a strategic interaction between firms at two points in the line when they compete (Hotelling, 1929). When the line is transformed into a polygonal or circular shape and the number of vendors considerably exceeds 2, the Hotelling Model's strategic interaction becomes more complex (Hayashi \& Tsuge, 2019; Kulin \& Kuenne, 1962). For biopharmaceutical companies, there is competition not only over R\&D location but also over time (Veugelers et al., 2008; Weber, 1929). It can be seen that the competition of biopharmaceutical companies in R\&D investment is characterized by tri-dimensionality, multidimensionality, and complexity. Therefore, the test of this strategic interaction needs to be evaluated at the global level, and the Moran's I index is a common measure for global analysis (Ou et al., 2015). The test results are summarized in Table 3.

As shown in Table 3, from 2015 to 2018, biopharmaceutical companies show a significant spatial autocorrelation in R\&D investment. This suggests an interdependence in $R \& D$ investment among neighboring biopharmaceutical companies, and this may be related to the concentration of technological innovation among these companies (Cooke, 2004; H. Zhang \& Bulcke, 2007; Hilliard \& Jacobson, 2011). Moran's I indexes are all positive, indicating that the biopharmaceutical companies' $R \& D$ investment has a positive spatial spillover effect, which is conducive to improving the efficiency of the technological innovation of neighboring biopharmaceutical companies (Kim et al., 2009). In terms of the development of China's biopharmaceutical industry, three major technology R\&D centers have been formed in the Yangtze River Delta, Pearl River Delta, and Bohai Rim (Mao \& Zheng, 2009). Drug companies in these R\&D centers collaborate closely and strategically with each other more frequently. Notably, such strategic interaction is not limited to these

Table 3 Moran's I index of R\&D Investment, 2015-2018

\begin{tabular}{lll}
\hline Year & Moran's I & P-value \\
\hline 2015 & $0.1201^{* *}$ & 0.019 \\
2016 & $0.1083^{* *}$ & 0.027 \\
2017 & $0.0905^{* *}$ & 0.017 \\
2018 & $0.1054^{* *}$ & 0.025 \\
\hline
\end{tabular}

$*$ and $* *$ are significant at 0.1 and 0.05 , respectively 
regions, and biopharmaceutical companies also have cross-city cooperation and interaction on R\&D investment (Jiang et al., 2017).

\section{Analysis of the influencing factors of biopharmaceutical companies' R\&D investment}

Biopharmaceutical companies formulate corresponding technology competition strategies to determine R\&D investment according to their situation and their competitors in a specific spatiotemporal context. In the polygonal or circular Hotelling model, spatial distance is an essential factor affecting biopharmaceutical companies' $R \& D$ investment. In this study, Model 1 is the spatial lag panel model with the distance factor. Model 2 investigates the spatial lag effect of total assets, and Model 3 examines the spatial lag effect of total employees. The results of the three spatial panel models with random effects are summarized in Table 4.

As shown in Table 4, in all the models, the square of the distance negatively affects the R\&D expenditure of biopharmaceutical companies, which is statistically significant. This indicates that for biopharmaceutical companies, the further away they are from the spatial

Table 4 Determinants of biopharmaceutical companies' R\&D expenditure

\begin{tabular}{|c|c|c|c|}
\hline & $\operatorname{lnRDE}$ & & \\
\hline & Model 1 & Model 2 & Model 3 \\
\hline Distance & $-0.002 *(-1.74)$ & $-0.002 *(-1.69)$ & $-0.002 *(-1.72)$ \\
\hline $\operatorname{lnTA}$ & $0.42 * * *(7.87)$ & $0.418 * * *(7.85)$ & $0.42 * * *(7.87)$ \\
\hline $\operatorname{lnTE}$ & $0.192 * * *(3.48)$ & $0.193 * * *(3.51)$ & $0.192 * * *(3.49)$ \\
\hline $\operatorname{lnSE}$ & $0.007 * * *(4.13)$ & $0.007 * * *(4.11)$ & $0.007 * * *(4.13)$ \\
\hline ROE & $0.008 * * *(5.22)$ & $0.008 * * *(5.21)$ & $0.008 * * *(5.22)$ \\
\hline $\operatorname{lnSTS}$ & $0.21 *(1.76)$ & $0.212 *(1.77)$ & $0.213 *(1.78)$ \\
\hline $\operatorname{lnTP}$ & $-0.058 * *(-2.3)$ & $-0.057 * *(-2.29)$ & $-0.058 * *(-2.3)$ \\
\hline $\operatorname{lnSS}$ & $-0.04 *(-1.74)$ & $-0.04 *(-1.75)$ & $-0.04 *(-1.74)$ \\
\hline Year & & & \\
\hline 2016 & $0.093 * * *(3.27)$ & $0.09 * * *(3.18)$ & $0.094 * * *(3.32)$ \\
\hline 2017 & $0.162 * * *(4.97)$ & $0.157 * * *(4.78)$ & $0.165^{* *}(5.08)$ \\
\hline 2018 & $0.325^{* * *}(8.69)$ & $0.321 * * *(8.54)$ & $0.331 * * *(8.93)$ \\
\hline Cons & $3.35 * * *(5.57)$ & $3.33 * * *(5.53)$ & $3.328 * * *(5.5)$ \\
\hline$\rho$ & $0.04 *(1.78)$ & $0.075(1.19)$ & $0.076(1.21)$ \\
\hline$\gamma$ & & & \\
\hline LnTA & & $0.085^{* *}(2.1)$ & \\
\hline $\operatorname{lnTE}$ & & & $0.061 *(1.85)$ \\
\hline /sigma_u & 1.076 & 1.076 & 1.075 \\
\hline /sigma_e & 0.323 & 0.323 & 0.323 \\
\hline Log likelihood & -870.557 & -869.947 & -870.429 \\
\hline Wald chi2 & $837.6^{* * *}$ & $839.95^{* * *}$ & $837.94 * * *$ \\
\hline Pseudo $\mathrm{R}^{2}$ & 0.328 & 0.327 & 0.328 \\
\hline Wald test of spatial terms & $3.18^{*}$ & $4.4 * *$ & 1.46 \\
\hline
\end{tabular}

$*, * *$, and $* * *$ are significant at $0.1,0.05$, and 0.01 , respectively 
gravity center of the biopharmaceutical industry's R\&D investment, the more likely they are to be in a marginal position in the R\&D space of the entire biopharmaceutical industry, and the less they invest in R\&D. This indicates that distance decay exists in the biopharmaceutical industry's R\&D space and the biopharmaceutical companies that are further away from the gravity center have less R\&D investment; that is, their R\&D investment decreases with an increase in distance (Bilbao-Osorio \& Rodríguez-Pose, 2004).

In the biopharmaceutical industry, the entire space is composed of a core, semi-periphery, and periphery, and it contains a sort of topology (Orsenigo et al., 1997). The area covered by the ellipse in Fig. 1 is the core area of the biopharmaceutical industry's R\&D space. Biopharmaceutical enterprises with relatively significant R\&D investments are clustered in this area, and these biopharmaceutical enterprises are close to the core areas of R\&D investment. Areas outside the ellipse can be considered as semi-peripheries, while areas far away from the ellipse are peripheries. Biopharmaceutical companies far from the ellipse are bound to be far from the core area of R\&D investment, and their R\&D investment is relatively small. The results presented in Table 4 show that the biopharmaceutical industry R\&D space has such a core-periphery topology structure.

In the biopharmaceutical industry's R\&D space, the distance between the spatial gravity center and biopharmaceutical enterprises refers not only to the physical distance but also the technological distance. The gravity center is determined according to the geographical distribution and R\&D investment of these companies. Therefore, even if the physical address remains the same, the distance from the spatial gravity center also changes because the center of gravity changes yearly. In the Hotelling model, competing enterprises tend to have "centralization," which is an inevitable result of profit maximization (Hotelling, 1929). The results of this study show that biopharmaceutical enterprise R\&D expenditure is negatively correlated with distance. Therefore, in the biopharmaceutical industry R\&D space, companies implement the "centralization" strategy by increasing R\&D investment to gain advantages in the biopharmaceutical industry technology competition. This study empirically verifies the equilibrium result predicted by the polygonal and circular Hotelling model(Hayashi \& Tsuge, 2019; Kulin \& Kuenne, 1962).

In Model 1 of Table 4, the spatial lag regression coefficient of the R\&D expenditure of biopharmaceutical enterprises is 0.049 , which is significant. This indicates that biopharmaceutical companies' R\&D activities have a positive spatial spillover effect (Cabrer-Borras \& Serrano-Domingo, 2007; Smrkolj \& Wagener, 2016). From the perspective of time effect, in the three models shown in Table 4, except for the regression coefficient of 2016 in Model 2, the regression coefficient of other years is positive and significant. This shows that biopharmaceutical companies' R\&D investment changes with time, increasing annually. This is a crucial way for biopharmaceutical companies to gain profits, and it ensures the trend of competition (Abdelaziz et al., 2008; Scherer, 2001).

In the present study, the spatiotemporal context is operationalized by space and time to evaluate the context-sensitive thesis, concerning the potential role of the contextual level of biopharmaceutical industry in the R\&D expenditure of biopharmaceutical companies. The aforementioned empirical research results show how the spatiotemporal context of the biopharmaceutical industry at the macro level, measured by distance and time, affects the R\&D expenditure of biopharmaceutical companies at the micro level. The empirical findings are consistent with the SSP theory, i.e., the spatiotemporal context will affect the behavior of biopharmaceutical companies, including R\&D investment $(\mathrm{Gu}, 2021 \mathrm{a}$, 2021b, 2020). In other words, this study supports the context-sensitive thesis. Therefore, the spatial distribution of the biopharmaceutical industry will exhibit core-peripheral 
characteristics, and the distance from the core area will have an impact on the R\&D investment of enterprises.

There are two possible explanations for this study's findings: one explanation relates to the important role of location (Cockburn \& Slaughter, 2010). The biopharmaceutical industry is a typical knowledge-intensive industry. Therefore, biopharmaceutical companies are often located near leading universities and research institutions to form a spatial cluster, such as the three famous biopharmaceutical clusters in Boston, San Francisco, and San Diego in the US, the Cambridge biopharmaceutical cluster in the United Kingdom, the Tokyo and Hokkaido biopharmaceutical clusters in Japan, the Denmark-Sweden Bio Valley, and the German biopharmaceutical demonstration zone. In China, biopharmaceuticals have formed an industrial spatial pattern centered on the Yangtze River Delta, Pearl River Delta, and Bohai Rim. Therefore, spatial context matters in determining the R\&D expenditure of biopharmaceutical companies.

The second explanation relates to the process of spatial competition (Iskakov \& Pavlov, 2009). Biopharmaceutical companies in different spatial locations have a sequence of $R \& D$ strategies, and the latter mover can observe the choices of those who act first and develop corresponding R\&D strategies accordingly. Therefore, this spatial competition is a dynamic game, that is, a "multi-stage game." This means that, in terms of time, the past R\&D expenditure of biopharmaceutical companies will affect the current decision, and the current decision will have an impact on the future. Therefore, the temporal context matters in determining the R\&D expenditure of biopharmaceutical companies.

In this study, the explanatory variables at the firm level can be regarded as control variables. The results of this study are consistent with those of previous studies. This study shows that company size is positively related to $R \& D$ expenditure. In the three models presented in Table 4, the regression coefficients for total assets and total employees are positive and significant. This is similar to DiMasi (2014)'s result. Sale expense as a percentage of gross revenue's impact on the biopharmaceutical company's R\&D funding is positive and significant (Prentis et al., 1988). The regression coefficient of the ROE is positive and significant, indicating that the more robust the profitability of biopharmaceutical enterprises, the more investment they spend on R\&D (Scherer, 2001). Moreover, the higher the shareholding ratio of the top 10 shareholders, the more the R\&D investment of biopharmaceutical enterprises (Gamble, 2000). Research has also shown that the higher the proportion of taxes payable in gross revenue, the lower the R\&D investment of biopharmaceutical enterprises. The higher the ratio of the staff salaries in the total revenue, the lower the biopharmaceutical enterprise's R\&D investment (MariannaMarino, 2016). This requires the government to cut taxes and fees on biopharmaceutical companies and provide certain subsidies for their innovation activities, which will help promote innovation and development (Choi \& Lee, 2017). Meanwhile, biopharmaceutical companies should also reasonably control their expenses on staff salaries by transforming themselves from labor-intensive enterprises to knowledge-intensive enterprises (Nightingale, 2000).

Furthermore, the regression coefficients of the spatial hysteresis effect of total assets and total employees in Models 2 and 3 are positive and significant. This indicates that total assets and total employees have a direct impact on the R\&D investment of biopharmaceutical companies and influence the R\&D expenditure of neighboring biopharmaceutical companies through indirect effects. In causal inference, the distinction between direct and indirect effects helps to explain the internal logic of interactive relationships (Hudgens \& Halloran, 2008). 
Table 5 Spatial panel regression model with spatial contiguity weights

\begin{tabular}{llll}
\hline & \multicolumn{3}{l}{$\operatorname{lnRDE}$} \\
\cline { 2 - 4 } & Model 4 & Model 5 & Model 6 \\
\hline $\begin{array}{l}\text { Distance } \\
\text { Year }\end{array}$ & $-0.003 * *(-2.38)$ & $-0.003 *(-1.81)$ & $-0.002 *(-1.79)$ \\
2016 & $0.102 * * *(3.45)$ & $0.098^{* * *}(3.39)$ & $0.098^{* * *}(3.39)$ \\
2017 & $0.18^{* * *(4.9)}$ & $0.171^{* * *}(5.03)$ & $0.172 * *(5.03)$ \\
2018 & $0.352 * * *(8.22)$ & $0.342 * * *(8.24)$ & $0.342 * * *(8.24)$ \\
$\rho$ & $0.05 *(1.83)$ & $0.073(1.06)$ & $0.003(0.97)$ \\
\hline
\end{tabular}

$*$, **, and $* * *$ are significant at $0.1,0.05$, and 0.01 , respectively. To highlight the key points, the regression results of the explanatory variables at the firm level do not appear in this table. However, further details of these regressions can be found in Appendix 1

\begin{tabular}{|c|c|c|c|}
\hline & \multicolumn{3}{|l|}{$\ln \mathrm{RDE}$} \\
\hline & Model 7 & Model 8 & Model 9 \\
\hline Distance & $-0.002 *(-1.69)$ & $-0.003 *(-1.79)$ & $-0.002 *(-1.66)$ \\
\hline \multicolumn{4}{|l|}{ Year } \\
\hline 2016 & $0.096 * * *(3.48)$ & $0.084 * * *(2.98)$ & $0.104 * * *(3.67)$ \\
\hline 2017 & $0.165 * * *(4.96)$ & $0.139 * * *(3.78)$ & $0.181 * * *(5.06)$ \\
\hline$\rho$ & $0.05^{*}(1.85)$ & $0.294(1.41)$ & $0.189(0.96)$ \\
\hline
\end{tabular}

$*$, **, and *** are significant at $0.1,0.05$, and 0.01 , respectively. To highlight the key points, the regression results of the explanatory variables at the firm level do not appear in this table. However, further details of these regressions can be found in Appendix 2

\section{Robustness check}

The empirical results in Table 4 are obtained using an inverse distance spatial weight matrix. If the spatial weight matrix changes, are these conclusions still valid? In other words, will the above-stated research conclusions change because of alterations in the spatial structure? This requires the use of different types of spatial weight matrices for robustness testing. Here, the spatial contiguity weight matrix is used for the regression. The spatial contiguity weight defines the weight between adjacent companies as 1 , and that between non-adjacent companies as 0 . Therefore, the spatial contiguity weight matrix is a symmetric matrix composed of 0 and 1 . The results obtained are summarized in Table 5. In terms of statistical significance, the results presented in Table 5 are the same as those provided in Table 4 . In terms of the magnitude of the coefficients, the results match the findings in Table 4. This shows that in the case of different spatial weights, the effect of the spatiotemporal context on the R\&D expenditure of biopharmaceutical companies remains unchanged.

This study focuses on listed biopharmaceutical companies in China from 2015 to 2018. However, the compliance may be incomplete. The effects of the spatiotemporal context should be tested for different time periods. Spatial regression analyses are performed for 
the time spans of 2015-2017 and 2016-2018. The results are summarized in Tables 6 and 7. The results in Tables 5 and 6 replicate those in Table 4. This shows that the conclusions of this research remain valid for different time spans.

This study has certain limitations that should be mentioned, which suggest three lines of future research. This study focused on the impact of the spatiotemporal context on the R\&D investment of biopharmaceutical companies under a single center of gravity. However, there are often multiple centers of gravity in reality. In addition to the global center of gravity, there are regional centers of gravity. In this case, the influence of the spatiotemporal context and its mechanism need to be further studied in the future. Regarding the endogeneity issues, as the aforementioned tests have shown, we adopt a variety of control variables and use panel models with various spatial contiguity weights in different time periods. However, even though these strategies are used to handle the empirical problem of potential endogeneity, endogeneity might still be a problem due to reverse causality. In addition, this study examines the innovative behavior of biopharmaceutical companies from the perspective of $R \& D$ investment, and in the future, the research can also be from the perspective of $R \& D$ output to compare it with the input.

\section{Conclusion}

To summarize, the current study provides new insights into the influence of the spatiotemporal context on biopharmaceutical companies' R\&D expenditures. Based on the research on the $\mathrm{R} \& \mathrm{D}$ expenditures of 284 listed biopharmaceutical companies in China, this study finds that the biopharmaceutical industry's R\&D space presents a "North (slightly east)-South (slightly west)" spatial pattern. Moreover, the core area of the biopharmaceutical industry's R\&D space presents a trend of spatial convergence. The spatial gravity center of this industry's R\&D investment has been shifting to the eastern coastal region. This spatiotemporal context will impact the R\&D investment of this sector. With the shift of the spatial gravity center, the distance between biopharmaceutical companies and the spatial gravity center also changes. The study further shows that this distance has a direct impact on the companies' R\&D. The greater the distance from the spatial gravity center of this industry's R\&D investment, the lower biopharmaceutical companies' R\&D expenditures. This finding attests to the important role of spatiotemporal context in the R\&D expenditure of biopharmaceutical companies, thus confirming the Chinese government's

Table 7 Determinants of biopharmaceutical companies' R\&D expenditure (2016-2018)

\begin{tabular}{llll}
\hline & \multicolumn{3}{l}{$\operatorname{lnRDE}$} \\
\cline { 2 - 4 } & Model 10 & Model 11 & Model 12 \\
\hline $\begin{array}{l}\text { Distance } \\
\text { Year }\end{array}$ & $-0.002 *(-1.77)$ & $-0.002 *(-1.7)$ & $-0.003 *(-1.78)$ \\
2017 & $0.077 * *(3.01)$ & $0.063 * *(2.32)$ & $0.08 * * *(3.04)$ \\
2018 & $0.244 * * *(7.98)$ & $0.239 * *(7.78)$ & $0.253 * * *(7.15)$ \\
$\rho$ & $0.053 *(1.88)$ & $0.27(1.27)$ & $0.035(0.2)$ \\
\hline
\end{tabular}

$*$, **, and *** are significant at $0.1,0.05$, and 0.01 , respectively. To highlight the key points, the regression results of the explanatory variables at the firm level do not appear in this table. However, further details of these regressions can be found in Appendix 3 
assumption that optimizing the spatial layout helps to promote the innovative activities of biopharmaceutical companies, thereby promoting the development of the biopharmaceutical industry (Tiong et al. 2010). Future work is welcomed to evaluate the main thesisthat spatiotemporal context matters in determining R\&D expenditure of biopharmaceutical companies-with data covering longer time spans and more regions worldwide.

\section{Appendix 1: Determinants of biopharmaceutical companies' R\&D expenditure (spatial contiguity weights matrix)}

\begin{tabular}{|c|c|c|c|}
\hline & \multicolumn{3}{|l|}{$\operatorname{lnRDE}$} \\
\hline & Model 4 & Model 5 & Model 6 \\
\hline Distance & $-0.003 * *(-2.38)$ & $-0.003 *(-1.81)$ & $-0.002 *(-1.79)$ \\
\hline $\operatorname{lnTA}$ & $0.43 * * *(8.08)$ & $0.428 * * *(8.04)$ & $0.428 * * *(8.04)$ \\
\hline $\operatorname{lnTE}$ & $0.184 * * *(3.33)$ & $0.185 * * *(3.36)$ & $0.185 * * *(3.36)$ \\
\hline $\operatorname{lnSE}$ & $0.007 * * *(4.14)$ & $0.007 * * *(4.14)$ & $0.007 * * *(4.14)$ \\
\hline ROE & $0.008 * * *(5.27)$ & $0.008 * * *(5.27)$ & $0.008 * * *(5.27)$ \\
\hline $\operatorname{lnSTS}$ & $0.211^{*}(1.76)$ & $0.212 *(1.77)$ & $0.212 *(1.77)$ \\
\hline $\operatorname{lnTP}$ & $-0.059 * *(-2.34)$ & $-0.058 * *(-2.33)$ & $-0.058 * *(-2.33)$ \\
\hline $\operatorname{lnSS}$ & $-0.037(-1.63)$ & $-0.038(-1.64)$ & $-0.037(-1.64)$ \\
\hline \multicolumn{4}{|l|}{ Year } \\
\hline 2016 & $0.102 * * *(3.45)$ & $0.098 * * *(3.39)$ & $0.098 * * *(3.39)$ \\
\hline 2017 & $0.18^{* * *}(4.9)$ & $0.171 * * *(5.03)$ & $0.172 * *(5.03)$ \\
\hline 2018 & $0.352 * * *(8.22)$ & $0.342 * * *(8.24)$ & $0.342 * * *(8.24)$ \\
\hline Cons & $3.718 * * *(5.76)$ & $3.733 * * *(5.72)$ & $3.733 * * *(5.72)$ \\
\hline$\rho$ & $0.05 *(1.83)$ & $0.073(1.06)$ & $0.003(0.97)$ \\
\hline \multicolumn{4}{|l|}{$\gamma$} \\
\hline $\operatorname{lnTA}$ & & $0.063 * *(2.05)$ & \\
\hline $\operatorname{lnTE}$ & & & $0.068 *(1.89)$ \\
\hline /sigma_u & 1.08 & 1.081 & 1.081 \\
\hline /sigma_e & 0.323 & 0.323 & 0.323 \\
\hline Log likelihood & -871.753 & -871.764 & -833.91 \\
\hline Wald chi2 & $833.71 * * *$ & $833.91 * * *$ & $837.94 * * *$ \\
\hline Pseudo $\mathrm{R}^{2}$ & 0.324 & 0.322 & 0.322 \\
\hline Wald test of spatial terms & $3.32 *$ & $4.03 * *$ & 1.51 \\
\hline
\end{tabular}

$*, * *$, and $* * *$ are significant at $0.1,0.05$, and 0.01 , respectively. 


\section{Appendix 2: Determinants of biopharmaceutical companies' R\&D expenditure (2015-2017)}

\begin{tabular}{|c|c|c|c|}
\hline & $\operatorname{lnRDE}$ & & \\
\hline & Model 7 & Model 8 & Model 9 \\
\hline Distance & $-0.002 *(-1.69)$ & $-0.003 *(-1.79)$ & $-0.002 *(-1.66)$ \\
\hline $\operatorname{lnTA}$ & $0.405^{* * *}(6.6)$ & $0.404 * * *(6.6)$ & $0.41 * * *(6.61)$ \\
\hline $\operatorname{lnTE}$ & $0.151 * *(2.36)$ & $0.153^{* *}(2.4)$ & $0.152 * *(2.37)$ \\
\hline $\operatorname{lnSE}$ & $0.008 * * *(3.5)$ & $0.008 * * *(3.36)$ & $0.008 * * *(3.48)$ \\
\hline ROE & $0.006^{* * *}(2.97)$ & $0.006^{* * *}(2.91)$ & $0.006^{* * *}(2.97)$ \\
\hline $\operatorname{lnSTS}$ & $0.262 *(1.95)$ & $0.272 * *(2.03)$ & $0.271 * *(2.02)$ \\
\hline $\operatorname{lnTP}$ & $-0.036(-1.18)$ & $-0.035(-1.15)$ & $-0.036(-1.19)$ \\
\hline $\operatorname{lnSS}$ & $-0.068^{* * *}(-2.63)$ & $-0.068 *(-2.61)$ & $-0.068^{* * *}(-2.62)$ \\
\hline Year & & & \\
\hline 2016 & $0.096 * * *(3.48)$ & $0.084 * * *(2.98)$ & $0.104 * * *(3.67)$ \\
\hline 2017 & $0.165 * * *(4.96)$ & $0.139 * * *(3.78)$ & $0.181 * * *(5.06)$ \\
\hline Cons & $3.549 * * *(5.26)$ & $3.532 * * *(5.24)$ & $3.457 * * *(5.1)$ \\
\hline$\rho$ & $0.05 *(1.85)$ & $0.294(1.41)$ & $0.189(0.96)$ \\
\hline$\gamma$ & & & \\
\hline $\operatorname{lnTA}$ & & $0.497 *(1.74)$ & \\
\hline $\operatorname{lnTE}$ & & & $0.273 *(1.87)$ \\
\hline /sigma_u & 1.067 & 1.067 & 1.065 \\
\hline /sigma_e & 0.308 & 0.307 & 0.308 \\
\hline Log likelihood & -717.85 & -716.482 & -717.116 \\
\hline Wald chi2 & $372.23 * * *$ & $376.61 * * *$ & $374.41 * * *$ \\
\hline Pseudo $\mathrm{R}^{2}$ & 0.318 & 0.315 & 0.318 \\
\hline Wald test of spatial terms & $3.27 *$ & $5.17 *$ & 3.93 \\
\hline
\end{tabular}

$*, * *$, and $* * *$ are significant at $0.1,0.05$, and 0.01 , respectively.

\section{Appendix 3: Determinants of biopharmaceutical companies' R\&D Expenditure (2016-2018)}

\begin{tabular}{llll}
\hline & \multicolumn{3}{l}{$\operatorname{lnRDE}$} \\
\cline { 2 - 4 } & Model 10 & Model 11 & Model 12 \\
\hline Distance & $-0.002^{*}(-1.77)$ & $-0.002^{*}(-1.7)$ & $-0.003^{*}(-1.78)$ \\
$\operatorname{lnTA}$ & $0.385^{* * *}(6.02)$ & $0.382^{* * *}(5.99)$ & $0.384^{* * *}(6.01)$ \\
$\operatorname{lnTE}$ & $0.234^{* * *}(3.61)$ & $0.238^{* * *}(3.67)$ & $0.235^{* * *}(3.63)$ \\
$\operatorname{lnSE}$ & $0.005^{* * *}(2.65)$ & $0.004 * * *(2.57)$ & $0.005^{* * *}(2.66)$ \\
$\mathrm{ROE}$ & $0.008^{* * *}(4.6)$ & $0.007 * * *(4.61)$ & $0.008^{* * *}(4.62)$ \\
$\operatorname{lnSTS}$ & $0.177(1.16)$ & $0.181(1.19)$ & $0.178(1.16)$ \\
$\operatorname{lnTP}$ & $-0.074 * * *(-2.65)$ & $-0.074 * * *(-2.66)$ & $-0.073^{* * *}(-2.65)$ \\
\hline
\end{tabular}




\begin{tabular}{llll}
\hline & \multicolumn{1}{l}{$\operatorname{lnRDE}$} & \\
\cline { 2 - 4 } & Model 10 & Model 11 & Model 12 \\
\hline InSS & $0.04(1.15)$ & $0.003(0.12)$ & $0.04(0.15)$ \\
Year & & & \\
2017 & $0.077^{* * *}(3.01)$ & $0.063^{* *}(2.32)$ & $0.08^{* * *}(3.04)$ \\
2018 & $0.244^{* * *}(7.98)$ & $0.239^{* * *}(7.78)$ & $0.253^{* * *}(7.15)$ \\
Cons & $3.47^{* * *(4.75)}$ & $3.458^{* * *(4.74)}$ & $3.437^{* * *}(4.68)$ \\
$\rho$ & $0.053^{*}(1.88)$ & $0.27(1.27)$ & $0.035(0.2)$ \\
$\gamma$ & & & \\
lnTA & & $0.477^{*}(1.83)$ & \\
lnTE & & & $0.107^{*}(1.91)$ \\
/sigma_u & 1.102 & 1.1 & 1.101 \\
/sigma_e & 0.276 & 0.275 & 0.276 \\
Log likelihood & -664.721 & -663.522 & -664.599 \\
Wald chi2 & $576.37^{* * *}$ & $580.8^{* * *}$ & $576.52^{* * *}$ \\
Pseudo ${ }^{2}$ & 0.311 & 0.31 & 0.312 \\
Wald test of spatial terms & $3.52^{*}$ & $5.9^{*}$ & 3.77 \\
\hline
\end{tabular}

$*, * *$, and $* * *$ are significant at $0.1,0.05$, and 0.01 , respectively.

Acknowledgements The author thanks for the support of National Social Science Foundation of China and would like to express thanks to the editor and two anonymous reviewers for their insightful comments and suggestions.

Funding The author(s) disclosed receipt of the following financial support for the research, authorship, and/ or publication of this article: This research is funded by the Social Science Foundation of China(17BSH122).

Access to data Jiafeng Gu had full access to all of the data in the study and takes responsibility for the integrity of the data and the accuracy of the data analysis.

\section{Declarations}

Conflict of Interest The author(s) declared no potential conflicts of interest with respect to the research, authorship, and/or publication of this article.

Ethical statement This research is funded by the Social Science Foundation of China(17BSH122). The authors declare that they have no conflict of interest. Because the data in this research is not collected from human subjects and is not involving Human Participants and/or Animals, EA is no needed in this research.

\section{References}

Abdelaziz, F. B., Brahim, M. B., \& Zaccour, G. (2008). R\&D Equilibrium Strategies with Surfers. Journal of Optimization Theory \& Applications, 136(1), 1-13.

Atewamba, C., \& Nkuiya, B. (2017). Testing the assumptions and predictions of the hotelling model. Environmental \& Resource Economics, 66(1), 1-35.

Bilbao-Osorio, B. A., \& Rodríguez-Pose, A. (2004). From R\&D to innovation and economic growth in the EU. Growth \& Change, 35(4), 434-455.

Breithaupt, H. (2003). China's leap forward in biotechnology. EMBO Reports, 4(2), 111-113.

Breton, M., Turki, A., \& Zaccour, G. (2004). Dynamic model of R\&D, Spillovers, And Efficiency Of Bertrand And Cournot Equilibria. Journal of Optimization Theory \& Applications, 123(1), 1-25. 
Breton, M., Vencatachellum, D., \& Zaccour, G. (2006). Dynamic R\&D with strategic behavior. Computers \& Operations Research, 33(2), 426-437.

Cabrer-Borras, B., \& Serrano-Domingo, G. (2007). Innovation and R\&D spillover effects in Spanish regions: A spatial approach. Research Policy, 36(9), 1357-1371.

Cellini, R., \& Lambertini, L. (2009). Dynamic R\&d with spillovers: Competition Vs cooperation. Journal of Economic Dynamics \& Control, 33(3), 568-582.

Chakma, J., Sun, G. H., Steinberg, J. D., Sammut, S. M., \& Jagsi, R. (2014). Asia's ascent-global trends in biomedical R\&D expenditures. New England Journal of Medicine, 370(1), 3-6.

Chakraborty, C., \& Agoramoorthy, G. (2010). A special report on India's biotech scenario: Advancement in biopharmaceutical and health care sectors. Biotechnology Advances, 28(1), 1-6.

Chen, J., Tian, Y., \& Shi, L. W. (2018). The impact of generic drug entry on market shares and prices of brand-name Drugs- evidence from Chinese pharmaceutical market. Value in Health, 21(2), S9.

Choi, J., \& Lee, J. (2017). Repairing the R\&D market failure: Public R\&D subsidy and the composition of private R\&D. Research Policy, 46(8), 1465-1478.

Chung, H., Eum, S., \& Lee, C. (2019). firm growth and R\&D in the korean pharmaceutical industry. Sustainability, 11(10), 2865.

Cockburn, I. M., \& Slaughter, M. J. (2010). The Global location of biopharmaceutical knowledge activity: New findings, new questions. Innovation Policy and the Economy, 10(1), 129-157.

Cohen, J. (2020). With global push for COVID-19 vaccines, China aims to win friends and cut deals. Science magazine.

Conlé, M. (2019). Recent developments in China's biopharmaceutical industry (2012-2017). Journal of Science and Technology Policy Management, 10(3), 686-707.

Cooke, P. (2004). The accelerating evolution of biotechnology clusters. European Planning Studies, 12(12), 915-920.

Daemmrich, A. (2009). Where is the Pharmacy to the World? International Regulatory Variation and Pharmaceutical Industry Location. HBS Working Paper,

Daniele, A. (1992). Patenting as an indicator of technological innovation: A review. Science and Public Policy, 19(6), 357-368.

David, E., Tramontin, T., \& Zemmel, R. (2009). Pharmaceutical R\&D: the road to positive returns. Nature Reviews Drug Discovery, 8(8), 609-610.

DiMasi, J. A. (2014). Pharmaceutical R\&D performance by firm size: Approval success rates and economic returns. American Journal of Therapeutics, 21(1), 26-34.

Eckhardt, B. (2004). The spatial pattern of localized R\&D spillovers: An empirical investigation for Germany. Journal of Economic Geography, 4(1), 43-64.

Egger, P., \& Pfaffermayr, M. (2006). Spatial convergence. Papers in Regional Science, 85(2), 199-215.

Gamble, J. E. (2000). Management commitment to innovation and ESOP stock concentration. Journal of Business Venturing, 15(5-6), 433-447.

Glaser., V. (1995). U.S. biopharm firms up R\&D spending 35\%. Nature Biotechnology, 13(7), 632-635.

Goel, R. K., \& Haruna, S. (2007). Cooperative and noncooperative R\&D with spillovers: The case of labormanaged firms. Economic Systems, 31(4), 423-440.

Golec, J., \& Vernon, J. (2008). Measuring US pharmaceutical Industry R\&D Spending. PharmacoEconomics, 26(12), 1005-1017.

Golec, J., \& Vernon, J. A. (2010). Financial effects of pharmaceutical price regulation on R\&D spending by EU versus US Firms. PharmacoEconomics, 28(8), 615-628.

Gong, J. (2002). Clarifying the standard deviational ellipse. Geographical Analysis, 34(2), 155-167.

Greenlund, K. J., Liu, K., Kiefe, C. I., Yunis, C., \& Burke, G. L. (1995). Impact of father's education and parental smoking status on smoking behavior in young adults: The CARDIA study. American Journal of Epidemiology, 142(11), 1029-1033.

$\mathrm{Gu}$, J. (2020). Spatiotemporal dynamics of the patent race: empirical evidence from listed companies in China. Asian Journal of Technology Innovation, 00, 1-28.

Gu, J. (2021a). Spatial dynamics between firm sales and environmental responsibility: The mediating role of corporate innovation. Sustainability, 13(4), 1648.

Gu, J. (2021b). Spatiotemporal context and firm performance: The mediating effect of strategic interaction. Growth and Change, 52(1), 371-391.

Hayashi, S., \& Tsuge, N. (2019). Necessary and sufficient condition for equilibrium of the Hotelling model on a circle.

Higon, D. A., Antolin, M. M., \& Mañez, J. A. (2010). Multinationals, R\&D and productivity: Evidence for UK Manufacturing firms. Discussion Papers in Economic Behaviour, 20(1110), 641-659(619). 
Hilliard, R., \& Jacobson, D. (2011). Cluster versus firm-specific factors in the development of dynamic capabilities in the pharmaceutical industry in ireland: A study of responses to changes in environmental protection regulations. Regional Studies, 45(10), 1319-1328.

Hotelling, H. (1929). The stability in competition. Economic Journal, 39, 41-57.

Hsieh, C. R., \& Lofgren, H. (2009). Biopharmaceutical innovation and industrial developments in South Korea, Singapore and Taiwan. Australian Health Review A Publication of the Australian Hospital Association, 33(2), 245-257.

Hudgens, M. G., \& Halloran, M. E. (2008). Toward causal inference with interference. Publications of the American Statistical Association, 103(482), 832-842.

IPRdaily (2019). 2019 Global Biomedical Industry Invention Patent Ranking (TOP100).

Iskakov, M., \& Pavlov, P. (2009). Secure strategy equilibrium in Hotelling's model of spatial competition. Access \& Download Statistics, 1(2), 911-922.

Jiang, S. Q., Shi, A. N., Peng, Z. H., \& Li, X. (2017). Major factors affecting cross-city R\&D collaborations in China: Evidence from cross-sectional co-patent data between 224 cities. Scientometrics, 111(3), 1251-1266.

Jing, D., \& Gou, Y. N. (2010). Corporate governance structure, managerial discretion, and the R\&D investment in China. International Review of Economics \& Finance, 19(2), 180-188.

Kai, G., \& Wang, W. (2012). The biopharmaceutical industry in China: History and future perspectives. Frontiers of Medicine, 6(2), 101-111.

Kim, M. K., Harris, T. R., \& Vusovic, S. (2009). Efficiency analysis of the US biotechnology industry: Clustering enhances productivity. AgBioforum, $12(3 \& 4), 422-436$.

Kleinknecht, A., \& Poot, T. P. (1992). Do regions matter for R\&D? Regional Studies, 26(3), 221-232.

Kodama, F. (2017). Emerging Patterns of Innovation: Sources of Japan's Technological Edge: Harvard Business School Press.

Kulin, H. W., \& Kuenne, R. E. (1962). An efficient algorithm for the numerical solution of the generalized weber problem in space economics. Journal of Regional Science, 4(2), 21-33.

Langer, E., \& Zhou, E. Y. (2007). Defining the Chinese biopharmaceutical market. Biopharm International, 20(1), 24-28.

Li, C., \& Zhang, J. (2013). Dynamic games of R\&D competition in a differentiated duopoly. Journal of Institutional \& Theoretical Economics Jite, 169(4), 660-679.

Liao, T. L., \& Lin, W. C. (2017). Corporate governance, product market competition, and the wealth effect of R\&D spending changes. Financial Management, 46(3), 717-742.

Mao, D., \& Zheng, Q. (2009). Encouraging an environment for pharmaceutical R\&D in China. Journal of Pharmaceutical Innovation, 4(3), 152-154.

Marianna, M., Pierpaolo, P., \& Sala, D. (2016). Additionality or crowding-out? An overall evaluation of public R\&D subsidy on private R\&D expenditure. Research Policy, 45(9), 1715-1730.

Matsumura, T., \& Matsushima, N. (2012). Welfare properties of strategic R\&D investments in Hotelling models. Economics Letters, 115(3), 465-468.

Menke, M. M. (1997). Managing R\&D for competitive advantage. Research Technology Management, $40(6), 40-42$.

MOST. (2019). 2019 China Life Science and Biotechnology Development Report. Science Press.

Nightingale, P. (2000). Economies of scale in experimentation: knowledge and technology in pharmaceutical R\&D. Industrial \& Corporate Change (2), 2.

Nivoixa, S., \& Nguyen, P. (2012). Characteristics of R\&D expenditures in Japan's pharmaceutical industry. Asia Pacific Business Review, 18(2), 225-240.

Omta, S. W. F., Boute, L. M., \& Engelen, J. M. L. V. (1994). Managing industrial pharmaceutical R\&D. A comparative study of management control and innovative effectiveness in European and Anglo-American companies. $R$ \& D Management, 24(4), 303-315.

Orsenigo, L., Pammolli, F., Riccaboni, M., Bonaccorsi, A., \& Turchetti, G. (1997). The evolution of knowledge and the dynamics of an industry network. Journal of Management \& Governance, 1(2), 147-175.

Ou, B., Zhao, X., \& Wang, M. (2015). Power of Moran's I Test for spatial dependence in panel data models with time varying spatial weights matrices. Journal of Systems Science \& Information, 3(5), 463-471.

Philippe, A., Christophe, C., \& Delphine, I. (2013). Competition, R\&D, and the cost of innovation: evidence for France. Oxford Economic Papers, 65(2), 293-311.

Prentis, R. A., Walker, S. R., Heard, D. D., \& Tucker, A. M. (1988). Pharmaceutical innovation and R\&D investment in the UK. Managerial \& Decision Economics, 9(3), 197-203.

Raghavendra, M. S., Raj, J. R., \& Seetharaman, A. (2012). A study of decrease in R\&D spending in the pharmaceutical industry during post-recession. International Journal of Academic Research, 4(45), $29-47$. 
Scherer, F. M. (2001). The link between gross profitability and pharmaceutical R\&D spending. Health Affairs, 20(5), 216-220.

Schmutz, B. P., \& Santerre, R. E. (2013). Examining the link between cash flow, market value, and research and development investment spending in the medical device industry. Health Economics, 22(2), $157-167$.

Schroeder, H. (2007). Do patent terms impact domestic R\&D spending in the pharmaceutical industry? Politiques De Sante, 2(3), 90-94.

Schuhmacher, A., Gassmann, O., \& Hinder, M. (2016). Changing R\&D models in research-based pharmaceutical companies. Journal of Translational Medicine, 14(1), 105-116.

Smrkolj, G., \& Wagener, F. (2016). Dynamic R\&D with spillovers: A comment. Journal of Economic Dynamics \& Control, 73(DEC.), 453-457.

Spithoven, A., \& Eacute, P. (2002). The Spatial Dimension of the R\&D expenditures in the Belgian enterprise sector. Brussels Economic Review, 45(4), 157-186.

Taggart, J. H. (2007). Determinants of the foreign R\&D locational decision in the pharmaceutical industry. $R \&$ D Management, 21(3), 229-240.

Tan, H. (2018). China's pharmaceutical industry is poised for major growth. Investing in Megatrends: CNBC.

Tellier, L. N., \& Vertefeuille, C. (2006). Understanding spatial inertia: centre of gravity, population densities, the weber problem and gravity potential. Journal of Regional Science, 35(1), 155-164.

Tiong, R., Conlé, M., \& Taube, M. (2010). Regional specialization in China's biopharmaceutical industry. Chinese Management Studies, 4(4), 339-359.

Veugelers, R., Belderbos, R., \& Lykogianni, E. (2008). Strategic R\&d location by multinational firms: Spillovers, technology sourcing, and competition. Journal of Economics \& Management Strategy, 17(3), 759-779.

Wang, E. C. (2010). Determinants of R\&D investment: The Extreme-Bounds-Analysis approach applied to 26 OECD countries. Research Policy, 39(1), 103-116.

Watanabe, C., Takayama, M., Nagamatsu, A., Tagami, T., \& Griffy-Brown, C. (2002). Technology spillover as a complement for high-level R\&D intensity in the pharmaceutical industry. Technovation, 22(4), 245-258.

Weber, A. (1929). Alfred Weber's theory of the location of industries (C. J. Friedrich, Trans.). Chicago: University of Chicago Press.

William, W., \& McCutchen, J. (1993). Estimating the impact of the R\&D tax credit on strategic groups in the pharmaceutical industry. Research Policy, 22(4), 337-351.

Zhang, H., \& Bulcke, D. V. (2007). China's pharmaceutical industry: cluster typologies and characteristics. Paper presented at the International Seminar on Knowledge Based Industries, Employment and Global Competitiveness, Delhi.

Zhang, Y. C., \& Li, S. L. (2009). High performance work practices and firm performance: Evidence from the pharmaceutical industry in China. International Journal of Human Resource Management, 20(11), 2331-2348.

Zhenzhen, L., Jiuchun, Z., Ke, W., Thorsteinsdóttir, H., Quach, U., \& Singer, P. A., et al. (2004). Health biotechnology in China-reawakening of a giant. Nature Biotechnology, 22(12), DC13-DC18. 